\title{
SOEP
}

SOEPpapers

on Multidisciplinary Panel Data Research
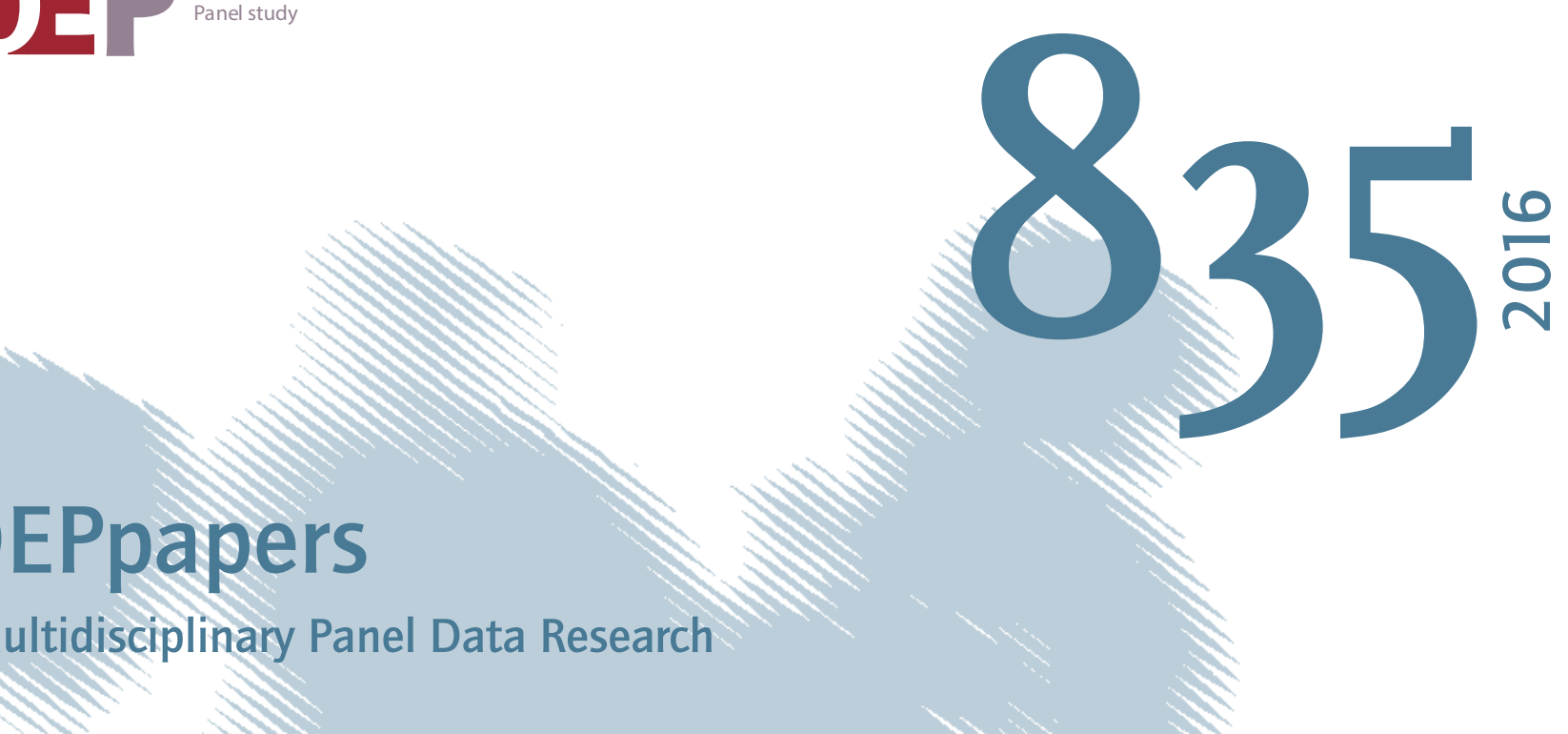

\section{Education and Health Across Lives and Cohorts: A Study of Cumulative Advantage in Germany}


This series presents research findings based either directly on data from the German SocioEconomic Panel study (SOEP) or using SOEP data as part of an internationally comparable data set (e.g. CNEF, ECHP, LIS, LWS, CHER/PACO). SOEP is a truly multidisciplinary household panel study covering a wide range of social and behavioral sciences: economics, sociology, psychology, survey methodology, econometrics and applied statistics, educational science, political science, public health, behavioral genetics, demography, geography, and sport science.

The decision to publish a submission in SOEPpapers is made by a board of editors chosen by the DIW Berlin to represent the wide range of disciplines covered by SOEP. There is no external referee process and papers are either accepted or rejected without revision. Papers appear in this series as works in progress and may also appear elsewhere. They often represent preliminary studies and are circulated to encourage discussion. Citation of such a paper should account for its provisional character. A revised version may be requested from the author directly.

Any opinions expressed in this series are those of the author(s) and not those of DIW Berlin. Research disseminated by DIW Berlin may include views on public policy issues, but the institute itself takes no institutional policy positions.

The SOEPpapers are available at http://www.diw.de/soeppapers

\section{Editors:}

Jan Goebel (Spatial Economics)

Martin Kroh (Political Science, Survey Methodology)

Carsten Schröder (Public Economics)

Jürgen Schupp (Sociology)

Conchita D'Ambrosio (Public Economics, DIW Research Fellow)

Denis Gerstorf (Psychology, DIW Research Director)

Elke Holst (Gender Studies, DIW Research Director)

Frauke Kreuter (Survey Methodology, DIW Research Fellow)

Frieder R. Lang (Psychology, DIW Research Fellow)

Jörg-Peter Schräpler (Survey Methodology, DIW Research Fellow)

Thomas Siedler (Empirical Economics)

C. Katharina Spieß ( Education and Family Economics)

Gert G. Wagner (Social Sciences)

ISSN: 1864-6689 (online)

German Socio-Economic Panel (SOEP)

DIW Berlin

Mohrenstrasse 58

10117 Berlin, Germany

Contact: Uta Rahmann | soeppapers@diw.de

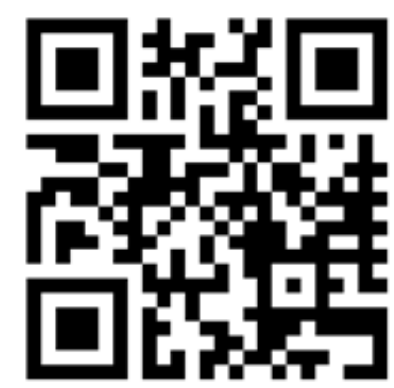




\title{
Education and Health Across Lives and Cohorts: A Study of Cumulative Advantage in Germany
}

\author{
Liliya Leopold \\ European University Institute \\ $\&$ \\ Thomas Leopold \\ University of Amsterdam
}

\begin{abstract}
Research from the United States has supported two hypotheses about health inequality. First, educational gaps in health widen with age - the cumulative advantage hypothesis. Second, this relationship has intensified across cohorts - the rising importance hypothesis. In this article, we estimate hierarchical linear models using 22 waves of panel data (SOEP, 19922013) to test both hypotheses in the German context, which contrasts sharply with the U.S. in the structural forces shaping health inequality. We consider individual and contextual influences on the core association between education and health, and assess gender differences in the process of cumulative advantage. Our overall results support the cumulative advantage hypothesis, as health gaps between higher and lower educated people widen with age. Further analyses reveal that this process is gender specific. Among women, educational gaps in health are small and remain stable. Among men, these gaps not only widen rapidly with age, but also increasingly across cohorts, supporting the rising importance hypothesis.
\end{abstract}




\section{Introduction}

Education is one of the most important predictors of health and mortality (Kitagawa and Hauser 1973). Beneficial effects of higher education and adverse effects of lower education on health are transmitted via health-related resources such as work environments, economic means, social support, and health behaviors, as well as the abilities to self-regulate and to cope with stressors (Ross and Mirowsky 2003). Over the past decades, the relationship between education and health has been intensely studied and found to be pronounced in all advanced societies (Mackenbach 2012).

This picture becomes less clear, however, when viewed from a life course perspective. Initial studies of age effects on educational health differences yielded contradictory findings of divergence, persistence, or even convergence over the life course (Ross and Wu 1996; House et al. 1994; Clark and Maddox 1992). This puzzle was later resolved by studies that situated educational health gradients within their socio-historical context. These studies have shown that seemingly persistent or convergent trajectories emerged as artifacts from analyses that ignored cohort patterns and their interactions with age and education (Lynch 2003). By considering cohort effects, recent investigations have produced consistent results: Educational gaps in health increase over the life course, supporting the cumulative advantage hypothesis, which predicts initial health-related advantages and disadvantages to accumulate with age (Willson et al. 2007). Moreover, this divergence was found to intensify across cohorts, a result that has been termed "rising importance of education for health" (Goesling 2007; Mirowsky and Ross 2008).

An important general conclusion from these studies is that cumulative advantage represents a context-specific phenomenon, whereby educational health trajectories are profoundly shaped by the social conditions surrounding different cohorts. Yet, the importance of context is still not widely recognized in the literature. The prime interest remains in 
processes of individual aging rather than the social context in which these processes unfold. In a similar vein, cumulative advantage theory - the principal framework guiding this research still emphasizes individual over structural forces of inequality.

The neglect of context is also reflected in the near absence of comparative research on the cumulative advantage hypothesis. Pertinent studies are almost exclusively based on U.S. data. Because of this focus, variation in national context has not been considered either theoretically or empirically. This is an important omission, given that the inclusion of other country contexts offers novel insight into key factors such as the role of educational systems in the creation of health inequality and the role of social policy in targeting this inequality.

In view of that, we designed the present study to contribute to the literature in two main ways. First, we consider individual and contextual influences on the core association between education and health, viewing cumulative advantage (a) from a life course perspective considering individual age-related change, (b) from a cohort perspective considering sociohistorical change, (c) from a comparative perspective considering cross-national differences, and (d) through a gendered lens considering how structural forces may differentially shape men's and women's health across their life courses.

Second, we conduct the first test for cumulative advantage and rising importance in the German context. Health inequality in Germany is shaped by two opposing social forces: on the one hand, an educational system that strongly connects social origin to social destination, hence promoting the accumulation of initial advantages and disadvantages; on the other, a welfare state designed to alleviate the resulting inequalities, comprising various measures that might inhibit divergence in educational health trajectories. Given that each of these aspects contrasts sharply with the U.S., Germany represents a particularly interesting setting to shed new light on both hypotheses. 
In our data from the German Socio-economic Panel Study (SOEP), information about self-rated health has been collected annually between 1992 and 2013, allowing us to trace individual health trajectories over more than twenty panel waves. This observation window is of unprecedented range, yielding large overlaps between age and cohort that are ideally suited to disentangle their effects.

\section{The Cumulative Advantage Hypothesis}

According to cumulative advantage theory (DiPrete and Eirich 2006), socioeconomic background and education are resources that structure the distribution of advantages and disadvantages as well as the onset and duration of exposure to environmental and social risks among individuals. By the mechanisms of path dependence and cumulative exposure, initial disparities increase over the life course (Dannefer 2003; O'Rand 1996). With regard to health, advantages such as material and psychosocial resources as well as disadvantages such as risky health behaviors accumulate over the life course, enforcing a steady increase of initial differences (Hayward and Gorman 2004).

Education plays a central role in this process as it stratifies all kinds of health-related resources between social groups (Ross and Wu 1996). Education reproduces and magnifies early advantages and disadvantages of social background and strongly determines income, occupational status and wealth in later life (Kerckhoff 1995). Depending on social background, children grow up in stable or unstable families, attend better or worse schools, and reach higher or lower occupational positions. These, in turn, protect them from or expose them to unfavorable working conditions and the "allostatic load" of stress associated with economic hardship (McEwen 1998). Moreover, education, or the lack thereof, promotes or impedes the acquisition of health-related resources such as learned effectiveness (Mirowsky 
and Ross 2003). As a combined result of these processes, the cumulative advantage hypothesis expects educational health differences to diverge over the life course.

Does educational health inequality increase, decrease or persist over the life course?

The cumulative advantage hypothesis has long been contested on theoretical and on empirical grounds. Although pioneering research supported the hypothesis (e.g., Ross and Wu 1996), other studies found that educational health gaps remained stable or even narrowed with age (e.g., Clark and Maddox 1992; Herd 2006; House et al. 1994). This conflicting evidence fueled an intense debate in the U.S. literature on health inequality over the life course.

Analysts who reported persistent or converging health gaps advanced the competing hypothesis of "age as leveler." This hypothesis postulates that educational differences in health increase throughout earlier and middle periods of the life course, persist up to older age, but decrease thereafter (House 1994). This late-life convergence has been mainly attributed to two factors: first, selective panel attrition and mortality among the lower educated; second, policy interventions that improve living conditions after retirement. The latter include Medicare, providing almost universal access to health care, and Social Security, ensuring a minimum standard of living among the disadvantaged. According to the age-asleveler hypothesis, these selection and policy effects prevail over the forces of accumulation (Herd 2006; Hoffmann 2011).

Research has shown that empirical support for the age-as-leveler hypothesis mainly resulted from the use of cross-sectional or short-term (two-wave) longitudinal designs (Beckett 2000; Noymer 2001; Lynch 2003). In such investigations, older respondents of lower education constitute a highly selective group of robust individuals, suggesting that diverging health trajectories among younger and middle-aged people were suppressed by the crosssectional nature of the data. An even more important limitation is that cross-sectional data 
confound age and cohort effects. This problem is not only methodological. Cross-sectional designs disregard that lives of individuals from different birth cohorts unfold in different socio-historical contexts.

This gives rise to actual - rather than selection-driven - cohort differences in educational health trajectories. Lynch (2003) has shown that health trajectories of educational groups vary markedly across cohorts. In fact, the expectation of identical trajectories across cohorts invokes a laboratory setting in which social conditions remain unchanged over time. Although this assumption appears preposterous on a theoretical level, it is implicit in empirical designs that examine age effects on health while ignoring cohort patterns. These designs lead to biased results on the cumulative advantage hypothesis if the distribution of health-related advantages and disadvantages between educational groups has changed across cohorts. If divergence increases across cohorts, for example, cross-sectional estimations will produce the opposite result, indicating convergence with age (Lynch 2003).

The key implication of these considerations is that an adequate test of the cumulative advantage hypothesis must disentangle age and cohort effects. This analytical separation takes account of the context in which educational health disparities develop. Recent U.S. studies that have disentangled age and cohort effects have unequivocally supported the cumulative advantage hypothesis (Willson et al. 2007; Mirowsky and Ross 2008).

\section{Is cumulative advantage a gendered phenomenon?}

Cumulative advantage has long been regarded as "unisex.” Recent research from the U.S. has suggested, however, that this process might not apply equally to men and women. These studies have argued that the intersection between gender and social stratification creates different contexts in which health trajectories develop. Because gendered norms and practices 
are socially stratified, higher or lower education may differentially structure health-related resources (Pudrovska 2014).

One theoretical perspective posits that educational gaps in health grow faster among men. According to the "reinforcement of advantage" hypothesis, men translate education more effectively into economic advantages, which multiply and reinforce each other in their beneficial or adverse effects on health (Ross and Mirowsky 2010). A competing perspective posits that educational health gaps accumulate more rapidly among women. According to the “resource substitution” hypothesis, education may improve women’s health more than men’s because women have fewer alternative socioeconomic resources (Ross and Mirowsky 2010). An additional argument highlights differential socialization. In their roles as future mothers, women are socialized to be more attentive to health matters (Reczek and Umberson 2012). In this process, education determines their capacity to understand health-relevant information, implement it into daily life, and thus, maintain good health (Pudrovska 2014).

Empirical evidence from the U.S. has supported the latter perspective, indicating stronger accumulation among women both in physical impairment (Ross and Mirowsky 2010) and mortality (Pudrovska 2014). Moreover, educational gaps have been found to widen more rapidly among women over the past decades (Liu and Hummer 2008).

\section{The Rising Importance Hypothesis}

The cumulative advantage hypothesis conceives of accumulation as a process that evolves within one cohort. An important follow-up question is how this process has changed across cohorts. In this regard, research on social disparities in health and mortality has suggested that educational inequality increases over time (Lauderale 2001; Elo and Preston 1996). Although these studies largely ignored life course patterns, their results reverberated through the U.S. literature in medical sociology, leading to the formulation of the "rising importance" 
hypothesis. This hypothesis states that cumulative advantage has intensified in newer cohorts (Mirowsky and Ross 2008).

The rising importance hypothesis is based on two arguments. Each of these arguments highlight changes that are specific to the U.S. context. The first focuses on change in healthrelated resources, such as material means and health behaviors. In the U.S., the relationship between education and income has intensified (Hout 2012). In the absence of welfare state intervention, quality of living, exposure to stressors, and access to health care are highly dependent on financial means (Lynch 2006). Through this pathway, growing educational differences in income may have increased health gaps in more recent cohorts (Goesling 2007).

The relationship between education and health-related behaviors has also intensified. Because of the epidemiologic transition from infectious to chronic diseases from the 1960s onward, the stock of information about health and preventive behaviors has expanded greatly. Higher educated individuals in the U.S. have not only disproportionally improved their health behaviors by optimizing their diet, exercising more, and smoking less, but also taken more advantage of new health services and medical technology (Harper and Lynch 2007; LlerasMuney and Lichtenberg 2002).

The second argument emphasizes compositional change and selection. With educational expansion and upward mobility, the group of lower educated individuals is constantly shrinking. As a result, lower educational groups might represent an increasingly negative selection of individuals on characteristics such as early health condition, cognitive ability, and sense of control (Haas 2006).

Recent U.S. studies have supported the rising importance hypothesis (Lynch 2003; Mirowsky and Ross 2008). Furthermore, the data were consistent with the main explanations that have been proposed for this trend, suggesting that widening health gaps emerge from 
distributional change in health-related resources (Lynch 2006), as well as compositional change of educational groups (Goesling 2007).

\section{The German Context}

Although recent studies have highlighted the context-dependent nature of cumulative advantage, knowledge about educational health trajectories remains almost exclusively limited to the United States. From a cross-national comparative perspective, it is important to consider whether the social forces that have shaped health trajectories within this national context apply to a lesser, similar, or even greater extent in other countries.

For the German context ${ }^{1}$ of the present investigation, extant research suggests marked differences compared with the U.S. In Table 1, we summarize these differences. Our comparison considers all key arguments on which the hypotheses of cumulative advantage and rising importance are based. As shown in the table, some of these arguments fit more closely with the German context (DE > US), whereas others fit more closely with the U.S. context (DE < US).

- Table $1-$

\section{Cumulative advantage of education for health in Germany}

The role of education as a sorting machine is a fundamental tenet of the cumulative advantage hypothesis. In Germany, this role is particularly salient. In contrast to the U.S., Germany is a textbook example for a selective and rigid school system, which translates educational degrees into occupational positions. These conditions favor the reproduction of initial

\footnotetext{
${ }^{1}$ All considerations refer to the West German context.
} 
advantages and disadvantages related to social origin, and stratify economic outcomes in later life along educational lines (Allmendinger 1989).

These properties are mainly attributed to early educational tracking and the strong vocational orientation of education. Based on their performance in 4th grade, children are tracked into three hierarchically structured educational pathways: lower secondary (Hauptschule), intermediate secondary (Realschule), and higher secondary (Gymnasium). Because performance at this young age highly depends on learning environments in families, early tracking strongly reproduces initial advantages and disadvantages of family background and exacerbates initial differences in cognitive ability, self-regulation, and economic means, suggesting pronounced accumulation of health-relevant resources in early life.

These early disparities are intensified by the vocational orientation of the German educational system and its close connection to the labor market (Shavit and Müller 1998). In contrast to the U.S. where employers focus more on performance on the job (Daly 2000), vocational qualifications are crucial for attaining occupational positions in Germany (Müller et al. 1998). Moreover, occupational mobility over the life course is exceptionally low in Germany. Throughout their working lives, individuals remain exposed to favorable or unfavorable working conditions associated with higher or lower occupational positions (Mayer et al. 2009).

Compared with the U.S., these characteristics of the German educational and occupational systems create an even more fertile breeding ground for the accumulation of initial advantages and disadvantages in health-related resources. The reverse picture, however, emerges for the remaining arguments behind the cumulative advantage hypothesis. These arguments pertain to the steady increase of educational disparities in health-related resources over the life course. All of these arguments fit more closely with the U.S. context. Regarding labor market factors, U.S. studies have highlighted material means as a driving force of 
cumulative health inequality (Lynch 2006). Less attention has been devoted to the fact that the link between material means and health is tightened by institutional characteristics that are specific to this context. In the absence of social protection against risks, the level of living, access to health care, and the degree of stress associated with negative life events strongly depends on material means. Moreover, the distribution of these resources is highly unequal, rendering those who are most susceptible to adverse events unable to respond.

In Germany, income inequality between educational groups is considerably smaller (Freeman 1994), and income is less strongly linked to health (Klein and Unger 2001). The German welfare state ensures a comparatively high standard of living regardless of economic means. Furthermore, employment protection is strong, payments in case of unemployment, long-term sickness or disability are generous (DiPrete 2002), health insurance is mandatory, and access to health care is universal.

Finally, educational gaps in health behaviors and related competencies are also more pronounced in the U.S. than in Germany. For the U.S., Mirowsky and Ross (2007) have shown that educational differences in sense of personal control increase markedly with age. A replication of this analysis with data from West Germany found no such effect (Specht et al. 2013). Related to that, highly educated individuals in the U.S. lead much healthier lifestyles than their lower educated counterparts. These differences in smoking, physical activity, and preventive health care are smaller in Germany (Cockerham et al. 1986; Pampel et al. 2015).

Consideration of these factors suggests that the life course pattern postulated by the cumulative advantage hypothesis - a steady increase of educational health disparities - may not apply to the German context. Unlike in the U.S. where policy measures aimed at reducing health disparities are implemented only in older age, the German welfare state targets health inequality throughout adulthood. 
Empirical evidence from Germany seemingly supports this view. No divergence was found in health trajectories between educational groups (Schöllgen et al. 2010; Knesebeck 2005). These results, however, are based on cross-sectional data. As noted, if health gaps increase with age (cumulative advantage) and this divergence intensifies across cohorts (rising importance), these processes offset each other in an estimation that does not separate age and cohort effects. In the presence of cumulative advantage and rising importance, cross-sectional analyses are unlikely to find evidence for either hypothesis. Consequently, it remains unclear whether findings of continuous or even converging educational health gaps result from the use of inadequate empirical designs or from successful intervention of the German welfare state.

\section{Rising importance of education for health in Germany}

Current U.S.-based formulations of the rising importance hypothesis emphasize two factors: (1) increasing inequality in the distribution and use of health-related resources, and (2) compositional change of educational groups. As shown in Table 1, the first factor fits more closely with the U.S. context; the reverse is true for the second factor.

Looking at change in the distribution and use of health-related resources, the U.S. have witnessed a steep rise of inequality in economic returns to education. In Germany, this trend was less pronounced, albeit still present. Compared to people born before and during the war, post-war and baby boom cohorts have experienced declining returns to education in terms of income and job security (Bookmann and Steiner 2006). These changes were most pronounced among the lower educated, whereas the higher educated maintained comparatively high and stable educational returns. Unlike in the U.S., however, these changes in the distribution of economic resources have not been accompanied by growing educational disparities in healthrelated behaviors (Pampel et al. 2015). Educational differences in smoking, drinking, physical 
exercise, and obesity have remained stable. A slight increase of educational differences in these behaviors was found only in the most recent cohorts (Kroll 2010).

The second factor motivating the rising importance hypothesis - compositional change of educational groups - fits more closely with the German context. Unlike in the U.S., where size and composition of higher as well as lower educational groups have changed considerably across cohorts, this trend was largely one-sided in Germany. Higher education expanded only modestly, and mainly among post-war cohorts. After this initial increase, the share of tertiary degrees has settled down at approximately 20 percent (Solga 2002) compared to about 40 percent in the U.S. (Goldin and Katz 2009). In contrast, the group of lower educated individuals (i.e., up to lower secondary degrees with vocational training) shrank dramatically from over 70 percent in pre-war cohorts to about 20 percent among those born in the 1970s (Solga 2002). This development is commonly attributed to the expanding service sector and "skill-biased technological change” (Autor et al. 1998). Jobs increasingly require higher levels of cognitive ability and knowledge. Since the 1980s, intermediate and, increasingly, higher secondary degrees became a requirement for accessing most vocational tracks in Germany (Klein 2011). The group of those who fail to attain these degrees is increasingly composed of the most disadvantaged people in terms of family background, cognitive skills, and other health-relevant resources. The group of higher educated, in contrast, has changed little in these respects (Jürges et al. 2011).

These considerations suggest that although the basic expectation of "rising importance" applies in both societies, the social forces driving this change are different. In the U.S., the rising importance of education for health has been primarily attributed to increasing advantages among the highly educated, such as growing economic returns and disproportionate improvements in health behaviors. Slower health declines in this group can be expected to drive the process of rising importance. In Germany, cross-cohort trends 
suggest the reverse pattern: Whereas the higher educated have not changed much in their educational returns, health behaviors, and compositional characteristics, the lower educated have experienced declines in returns to education and become more negatively selected on health-relevant characteristics. The rising importance of education for health should therefore result from steeper health declines among the lower educated, rather than flatter health declines among the higher educated.

\section{Gender differences}

In recent U.S. studies, educational health gaps were found to grow faster among women (Pudrovska 2014; Ross and Mirowsky 2010), pointing to gender differences in the process of cumulative advantage. In the German context, consideration of such differences is particularly important, as the structure of the life course is deeply divided along gender lines. Compared with the U.S., Germany offers two sharp contrasts.

First, the "resource substitution” hypothesis - which has been supported in the U.S. is less applicable to the life courses of German women. Upward marriage has long been the norm, weakening the link between women's level of education and their social position (Blossfeld 2009). Moreover, after motherhood, most women either left the labor force for good or returned only on a part-time basis (Blossfeld and Jaenichen 1992). Both of these characteristics constitute pathways through which German women were able to compensate for a lack of education.

Second, the "reinforcement of advantage” hypothesis - which has not been supported in the U.S. - fits closely with the life courses of German men. This applies especially to two critical links between education and health - labor-market outcomes and health behaviors (Boockmann and Steiner 2006). The German welfare state has long been organized around a male-breadwinner model that encourages gender specialization by combining tax incentives with low coverage of public childcare (DiPrete 2002). As a result, the labor market factors 
highlighted by the cumulative advantage hypothesis apply more strongly to men's than to women's life courses in Germany. The same is true for risky health behaviors. In this domain, educational differences are much larger among men. In smoking prevalence, the gap amounts to twenty-six percentage points among men (30\% of high educated and $56 \%$ of low educated Germans smoke), compared to only eight percentage points among women (20\% versus 28\%) (Pampel 2010).

\section{Data and Method}

\section{Sample}

Our analysis is based on data from the German Socio-Economic Panel Study (SOEP), a largescale, representative household and individual study (Wagner et al. 2007). In 1984, the SOEP started in West Germany with a sample population of approximately 12,000 individuals living in 6,000 households. Since 1992, the SOEP collects data about self-rated health at each annual wave. ${ }^{2}$ Our analysis draws on these data from an observation period between 1992 and 2013, yielding up to 21 measurements of self-rated health per individual.

In 1992, the anchor year of our study, the sample comprised 13,397 individuals. From this sample, we excluded immigrants and persons from the Former GDR, limiting the study population to West Germans. These sample restrictions ensured that individuals shared a common context with regard to educational degrees, returns to those degrees, and life conditions associated with cohort membership. We further constrained the sample to persons born between 1930 and 1968. Most men born before 1930 were enlisted to fight in the war and might constitute a particularly selective group of survivors. The upper bound of 1968 marked the end of the baby boom cohorts. After all restrictions, our analytic sample consisted

\footnotetext{
2 The only exception is the 1993 wave.
} 
of 4,629 individuals aged 24 to 62 in the anchor year of 1992, comprising 68,402 personyears across the observation period until 2013.

The SOEP data combine a large range of cohorts with an extensive window of observation. A major benefit of these data is that they allow for two types of analyses: First, a model in which linear change across cohorts is captured by interactions with age and education. This is a common approach in analyses of cumulative advantage (Willson et al. 2007). Second, models in which educational health trajectories are analyzed for different groups of cohorts, which are separated on theoretical grounds.

Given the large age overlaps between cohorts in our sample, our data yield a nuanced picture of cohort effects, allowing for linear and non-linear change. For the non-linear cohort analysis, we assigned respondents to three groups: (1) pre-war and war cohorts born between 1930 and 1945, (2) post-war cohorts born between 1946 and 1956, and (3) baby boom cohorts born between 1957 and 1968. These groups are not equal in span, but theoretically meaningful in the sense that their life courses were shaped by similar socio-historical conditions.

\section{Measure of health}

Self-rated health (SRH), is widely regarded as a valid measure of health. It is highly correlated with morbidity and functional limitations and constitutes a potent predictor of mortality (Idler and Benyamini 1997). In the SOEP, data about SRH are based on the annual survey question "How would you describe your current health?" Respondents answer on a scale from 1 (very good) to 5 (bad). We reverse-coded this variable so that lower values indicated worse health. 


\section{Measures of cohort and age}

For the linear cohort model, we centered birth year at the mean age of entry, equaling zero for those who were initially observed at the age of 41 in the year 1992 (i.e., born in 1951). Higher values of this cohort variable denote older cohorts. Age was measured in years, ranging from 24 to 83 . For the analysis of the linear cohort model, we centered the age variable at the grand median of 49 years. In the non-linear cohort model, age ranged from 47 to 83 in the pre-war and war cohort, from 36 to 67 in the post-war cohort, and from 24 to 56 in the baby boom cohort. For this model, we centered age at the minimum of each cohort. Similar to comparable U.S. studies (Willson et al. 2007; Lynch 2003), a linear function provided the best representation of age effects on health in all models. Table 2 presents descriptive statistics for the total sample and separately by the three cohort groups.

- Table 2 -

\section{Measures of education}

In U.S. studies of health inequality, education is commonly measured in years of schooling. In the present study, we instead used indicator variables for educational degrees. There are two reasons for this. First, a growing body of evidence suggests that the relationship between education and health is non-linear, given that incremental increases in years of education do not translate into similar benefits for health (Zajacova et al. 2012). Second, in the German context, meaningful differences are better captured by educational degrees than by years of education. Due to educational tracking of students into three separate school forms, individuals who attended different tracks (but for the same number of years) differ substantially in health-relevant characteristics such as family resources and cognitive ability. Moreover, as explained above, institutional characteristics such as entry requirements in the 
labor market render educational degrees and especially vocational qualifications more important than years of schooling for economic outcomes in adult life (Bookman and Steiner 2006).

- Figure 1 -

We measured educational degrees by the CASMIN classification. This variable indicates the highest educational degree reported by respondents within the observation period. Figure 1 shows the distribution of educational degrees in the three cohort groups separately by gender. We grouped the CASMIN categories as follows: the bottom category comprised individuals holding lower secondary degrees with completed vocational qualification or less (CASMIN 1a-1c); intermediate education ranged from intermediate secondary degrees to higher secondary degrees with vocational qualification (CASMIN 2a2c); the top category included respondents holding tertiary degrees (CASMIN 3a-3b). As described above, educational expansion in post-war Germany involved a shift primarily from lower to intermediate levels of education, whereas the proportion of higher educated individuals changed less. These trends are clearly recognizable in Figure 1.

\section{Controls for period effects}

To test the hypotheses of cumulative advantage and rising importance, our analysis focused on educational differences in the effects of age and cohort. The age effect indicates health declines within individuals, as they grow older. The cohort effect captures health differences between individuals, arising from their "unique location in the stream of history" (Ryder 1965, p. 844), which exposes people of similar age to the same socio-historical conditions. To estimate both effects from longitudinal data, it is important to control for a third source of temporal variation in health: Period effects are social changes that occur across the 
observation window and simultaneously affect the health of all individuals, irrespective of their age.

There is no technical solution to control for period in a model that includes age and cohort, because the three terms are exactly mathematically dependent. One way to circumvent this identification problem is to exclude period from the model, assuming that these effects are zero. Previous research on cumulative advantage and rising importance is implicitly based on this assumption, given that period effects have not been considered either theoretically or empirically.

To account for this potential source of bias in the estimation of age and cohort effects, we adopted a factor characteristic approach that represents period effects by measures of health-relevant changes across the observation window (O’Brien 2015). This approach avoids the identification problem by associating period with its substantive characteristics.

Economic shifts are known to affect health across age groups. Our factor characteristics include two measures of economic shifts: (a) the unemployment rate, and (b) year-to-year change in GDP for every year between 1992 and 2013. These characteristics were only slightly correlated throughout our observation window $(r=0.09)$. Although GDP has frequently been used in comparative research on health inequality, research has shown that unemployment captures health-relevant effects most directly (Tapia-Granados 2005).

In addition, we introduced two factor characteristics to account for the possibility that medical progress may improve population health and wellbeing. First, we used a measure of yearly health expenditures as a share of GDP. This variable captures medical progress in a broad sense, including expenditures on the prevention of diseases, access to medical care, diagnostics, and treatments. Second, we included a population measure of well-being. This measure is related to the utilization of and satisfaction with health care, and is considered a 
reliable indicator for subjective dimensions of changes in the quality of health care (Blumenthal et al. 2015). To measure wellbeing at population level, we used SOEP data on global life satisfaction measured on an 11-point Likert scale. Based on the entire sample of West German natives observed between 1992 and 2013 ( $N=$ 215,081 observations), we calculated an age-adjusted measure of average wellbeing for every year of our observation period. Due to refreshment samples, each of the SOEP waves can be considered a representative sample of the German population (Wagner et al. 2007).

\section{- Figure 2 -}

Figure 2 illustrates year-to-year changes in all four factor characteristics. We tested different functions to represent potential effects of the factor characteristic variables on health. Based on these tests, we included unemployment rates in linear and quadratic form, and all remaining factor characteristics in linear form.

\section{Controls for dropout}

To control for non-random dropout associated with poor health, we applied the method suggested by Chen, Yang, and Liu (2010), introducing direct controls for panel attrition. We constructed two time-constant indicator variables for whether respondents (a) had left the panel or (b) had died before the most recent wave of 2013. We included these controls to account for the possibility that later dropouts were in worse health compared to those remaining in the panel (Chen et al. 2010: 135). As shown in Table 2, nine percent of respondents selected in 1992 died across the observation period until 2012. Another 59\% left the panel for other reasons. The average number of annual observations per respondent was 15. 


\section{Analytic strategy}

We estimated change in SRH using hierarchical linear models (HLM). Our data included up to 21 observations per person, measured at yearly intervals. These repeated observations (level 1) were nested within persons (level 2). The HLM estimation accounts for heterogeneity in health trajectories, allowing individual age trajectories to differ in their starting levels (random intercepts) and rates of change (random slopes). The estimation of HLM provided information about mean health trajectories (growth curves) as well as individual variation around the average curves. The equations for the model are located in the Appendix.

An appropriate analytical strategy to estimate change in the relationship between education and health is to account simultaneously for change with age, change across cohorts, and their interactions (Lynch 2003; Willson et al. 2007; Mirowsky and Ross 2008). This approach translates into an empirical model that includes age, cohort, and education as well as two-fold and three-fold interactions between these variables.

Although our data track individuals over an exceptionally long period of time, they do not cover the entire life courses of different birth cohorts. Hence, the basic model combines individual trajectories which start and end at different ages into one extrapolated cohort to estimate change in health across the entire age range. Although cohort effects are modeled by interactions, differences can only emerge within the parametric constraints of a linear model. To overcome this restriction, we added a second analytical step in which we replaced the linear cohort variable by a categorical variable distinguishing between three cohort groups. This approach allowed to model flexible age trajectories within each cohort, and to account for non-linear patterns of change across cohorts. 
As noted, there are strong theoretical reasons to expect gender differences in the extent to which processes of cumulative advantage have shape health trajectories, especially in the German context. To gain insight into such differences, we complemented the analysis by separate models for men and women.

\section{Results}

In Table 3 we present the results of the linear cohort model for the total sample (Model 1), and separately for the subsamples of men (Model 2) and women (Model 3). For a test of the cumulative advantage hypothesis, the main interest is in educational differences in the slope of age (Table 3). The main effect of age pertains to the omitted category of lower educated people. The age slopes for intermediate and higher educated people are obtained by adding their interaction effects to this main effect. Positive interaction terms indicate that age slopes are flatter (i.e., health declines slower) in these groups. This is what the cumulative advantage hypothesis predicts.

For a test of the rising hypothesis, the focus is on cross-cohort change in the interactions between age and education. This change is indicated by a three way interaction between age, education, and cohort. In the models shown in Table 3, the two-way interactions between age and education are defined for the centered cohort variable equaling zero (i.e., for the cohort of 1951). In our specification, higher values of the cohort variable indicate older cohorts. Consequently, negative three-way interactions with cohort would indicate that cumulative advantage of education for health is less pronounced in older than in younger cohorts. This is what the rising importance hypothesis predicts. 
Results on the cumulative advantage hypothesis

In Model 1, pertaining to the full sample, the interactions between age and education show that higher educated people experienced slower health declines than lower educated people. This finding supports the cumulative advantage hypothesis and contradicts previous crosssectional studies from Germany (Knesebeck 2005; Schöllgen et al. 2010). In contrast to these studies, our model not only disentangles age and cohort effects but also controls for possible period effects as well as selection effects related to panel attrition and death.

Next, we tested for gender differences in cumulative advantage. Models estimated for subsamples of men (Model 2) and women (Model 3) revealed vastly different patterns. Compared with the full sample, the size of the interaction effect between age and higher education more than doubled in the male subsample, suggesting that cumulative advantage was much more pronounced in men. Results for the female subsample further showed that cumulative advantage was, in fact, limited to men.

\section{- Figure 3 -}

Figure 3 illustrates the results for the full sample (left panel), the male subsample (middle panel), and the female subsample (right panel). Each graph shows predicted trajectories of SRH for higher and lower educated individuals. The curves pertain to the average cohort (born 1951) of our sample, as we fixed all covariates at their means. A comparison between the three graphs shows that cumulative advantage emerged as the overall pattern only because this process was so strong among men. Among women, educational health gaps even narrowed with age, although this convergence was slight and statistically insignificant. Importantly, the absence of cumulative advantage in women was not due to slower health declines of the lower educated, but to faster declines among the higher educated. 
Within the male subsample, the educational health gap widened at a rapid pace. To evaluate the size of this effect, it is instructive to compare the age at which educational groups crossed the level of "acceptable" health (i.e., descending below the value of 3). Among lower educated men, this occurred already in their late 50s; among higher educated men, in their early 80 s - more than twenty years later in life.

\section{Results on the rising importance hypothesis}

Next, we turn to the second guiding hypothesis, which postulated a rising importance of education for health. Given the absence of cumulative advantage in women, our test focused on the male subsample. ${ }^{3}$ In Model 2, the two-way interaction between high education and cohort was negative, indicating that educational health gaps at the median age of 49 were slightly smaller in older cohorts. Furthermore, the negative sign of the three-way interaction between age, high education, and cohort was consistent with the rising importance hypothesis, indicating that health gaps increased more slowly in older cohorts of men.

\section{- Table 4 -}

As noted, the models shown in Table 3 are limited in capturing only linear change across cohorts. In Table 4, we examine the rising importance hypothesis in more detail, comparing health trajectories of pre-war and war cohorts to post-war cohorts and baby boom cohorts of German men. For ease of interpretation, we illustrate the key findings from Table 4 in two ways. First, we plot the curves derived from this model in Figure 4. The figure shows

\footnotetext{
${ }^{3}$ We also examined the rising importance hypothesis among women. Although Model 3 did not indicate cumulative advantage, these results do not necessarily contradict the rising importance hypothesis, as a linear cohort model might suppress a trend that emerges only among the most recently born. In view of that, we examined women's health trajectories separately for the three cohort groups. In the pre-war and war cohort, the low number of women who had obtained higher education $(n=42)$ precluded a reliable estimation of health differences between this group and lower educated women. In post-war and baby boom cohorts, we found no evidence for cumulative advantage of education for health. Our results for women, thus, were inconsistent with the cumulative advantage as well as the rising importance hypothesis.
} 
the large overlaps between age and cohort, which allow us to disentangle their effects. Second, based on these predicted trajectories, we calculated health gaps at the lower and upper bounds of age overlaps between the three cohort groups. Table 5 shows these health gaps, measured in scale points of SRH, at each of these overlapping ages. The rows of Table 5 pertain to cumulative advantage, showing age-related increase of health gaps within each cohort; the columns pertain to rising importance, showing cross-cohort change in the size of these gaps measured at overlapping ages.

- Figure 4 -

- Table 5 -

With regard to the rising importance hypothesis, Figure 4 and Table 5 show three notable patterns. First, health trajectories between lower and higher educated men diverged in every cohort. Second, in line with the rising importance hypothesis, health gaps increased across cohorts. Gaps measured at the age of 56, for example, more than doubled from approximately 0.2 scale points in the oldest cohorts to more than 0.5 scale points in the youngest cohorts (Table 5). Third, this trend was primarily produced by steeper health declines among the lower educated. Lower educated men who belonged to the post-war and baby boom cohorts fell below the level of "acceptable” health already in their mid-fifties. In the oldest cohort of lower educated men, this occurred approximately ten years later in life (Figure 4). Age slopes of higher educated men changed little across cohorts. Overall, these findings lend qualified support to the rising importance hypothesis, suggesting that the rate of cumulative advantage accelerated among men born in the post-war years, and that this shift was centered around the lower educated who experienced steeper health declines.

Finally, we turn to the period controls included in all models. Overall, the results indicated that periodic influence on health was minor, although the negative effects of 
unemployment and the positive effects of wellbeing were statistically significant in all models. For example, shifting unemployment from its minimum (6.8 \% in 2012) to its maximum (11.7\% in 2005) involved an average drop of only 0.05 scale points in SRH

(Model 1). An analogous increase from the empirically observed minimum of wellbeing (6.9 in 2004) to its maximum (7.3 in 2013) was associated with a rise of only 0.04 scale points in SRH. The remaining period effects were even smaller.

\section{Discussion}

According to cumulative advantage theory, health gaps between social groups emerge from broader patterns of social inequality. Education plays a central role in this process, reproducing initial social disparities and shaping health trajectories as people age. A key tenet of this perspective is the expectation of widening health gaps between educational groups over the life course.

In recent years, tests of the cumulative advantage hypothesis have been refined by greater attention to the social conditions in which individual health trajectories unfold. This line of research has not only led to methodological progress but also spawned new theoretical perspectives. These include the rising importance hypothesis, which predicts cumulative advantage to intensify across cohorts, and competing hypotheses about gender differences, suggesting that cumulative advantage is a gendered phenomenon.

Despite these recent advances, the context-specific nature of cumulative advantage is still not widely recognized, either theoretically or empirically. In the present study, we considered individual change with age and socio-historical change across cohorts as well as gender differences and cross-national differences in these processes. Given that previous research on cumulative advantage of education for health has focused almost exclusively on 
the U.S., our use of German data allowed us to view cumulative advantage through a comparative lens to gain further insight into the structural forces shaping health inequality across lives and cohorts.

Our comparative theoretical framework highlighted differences between Germany and the U.S. in various health-relevant factors on which the hypotheses of cumulative advantage and rising importance are based. These include the role of the educational system in reproducing initial advantages and disadvantages related to social origin and stratifying economic outcomes in later life; the role of the welfare state in targeting the steady increase of educational disparities in health-related resources over the life course; change over time in the distribution of health-relevant resources and the composition of educational groups; and the gendered structure of the life course differentially exposing men and women to the risk factors driving processes of accumulation.

Our empirical analyses examined health inequality over the adult life course in Germany, offering the first empirical assessment of the cumulative advantage and rising importance hypotheses in this context. Compared with the U.S., our results revealed two notable differences. First, empirical support for the cumulative advantage hypothesis was limited to health trajectories in men. Among women, we found no evidence for cumulative advantage, as the rates of health decline did not differ between the higher and the lower educated. Women did not translate higher education into slower health declines, whereas men reaped these benefits throughout all major stages of the adult life course. These results contrast sharply with U.S. findings indicating that cumulative advantage not only pertains to both sexes, but is stronger among women (Ross and Mirowsky 2010; Pudrovska 2014).

In our theoretical framework, we argued that critical links between education and health - in particular labor market factors and health behaviors - are much stronger among men than among women in Germany. We note, however, that we could not test these mechanisms 
directly in the present study. An alternative interpretation links the absence of cumulative advantage in women to the individual versus household income debate. In our study cohorts, women's socioeconomic status was largely determined by their partners' resources, potentially weakening the relationship between women's education and health. Due to the prevalence of upward marriage, however, this argument would suggest slower health declines among lower educated women rather than faster health declines among higher educated women. Our data showed the opposite pattern. We can only speculate about why higher educated women did not benefit as much from their education as men did. One possible reason are labor market disadvantages compared to German men, as higher educated women of our study cohorts had lower chances of attaining higher occupational positions and incomes (Sørensen and Trappe 1995). Additionally, their late and low fertility (Kreyenfeld 2010) could have neutralized further health benefits, given that these characteristics are associated with various health risks, the most severe of which is breast cancer (Matthews et al. 1999).

In research on health inequality, theoretical formulations and empirical tests of the cumulative advantage hypothesis are still largely gender-blind. In view of our findings, greater attention to such differences is warranted, particularly in studies that examine whether evidence from the U.S. can be generalized to other societies. The opposing patterns found for the U.S. and Germany provide compelling evidence for the importance of structural forces that have differentially shaped health trajectories of men and women in these societies.

Our findings on change across cohorts showed that cumulative advantage intensified, as predicted by the rising importance hypothesis. In contrast to the U.S., however, this trend was not only limited to men, but also took a different form. It was attributable to steeper health declines among the lower educated, starting in post-war cohorts of German men. In the U.S., the rising importance of education for health emerged as a combined outcome of slower 
health declines among the higher educated accompanied by faster health declines among the lower educated (Mirowsky and Ross 2008).

Again, these differences highlight the potential for comparative research, showing how health trajectories are differentially shaped by the context in which they unfold. In Germany, changes in returns to education and compositional change in health-relevant characteristics were negligible among higher educated men. The lower educated, in contrast, became more negatively selected and faced substantial declines in educational returns (Solga 2002). In the U.S., increasingly adverse conditions among the lower educated were accompanied by increasingly favorable conditions among the higher educated (Hout 2012). These crossnational differences are broadly consistent with our findings on the rising importance hypothesis. We note, however, that more precision is necessary in future comparative research to unravel whether, and to what extent, the proposed mechanisms have produced the observed patterns.

Considering the rising importance hypothesis, we further note that although processes of cumulative advantage have spared our study cohorts of women, this might change among the more recently born. Especially among women born in the 70s and 80s, education became more relevant to various life course outcomes. Examples are the narrowing gender gap in labor force participation, women's increasing economic returns to education (Fitzenberger and Wunderlich 2003), and growing differences in risky health behaviors such as smoking (Schulze and Mons 2006). Moreover, the proportion of higher educated women surged upward in these cohorts, whereas the group of lower educated women shrank, suggesting increasingly negative selection on health-relevant characteristics. In view of these shifts, we consider it important to explore whether processes of cumulative advantage of education for health have commenced among more recent cohorts of German women. 
In future studies of cumulative advantage and rising importance, the adequate separation of age and cohort effects - both theoretically and empirically - remains an important analytical challenge. In this regard, the present study has contributed in two main ways. First, in following a large range of study cohorts over an observation period spanning more than two decades, our data were ideally suited to test theoretical ideas about non-linear cohort effects. Given the extensive overlap between age and cohort in these long-run panel data, our analysis no longer relied on the assumptions of a synthetic cohort model (e.g., Mirowsky and Ross 2008). As equally rich panel data about health currently become available in other countries, we expect that novel insight can be gained from future tests of both hypotheses.

Second, as longer observation periods give rise to period effects, we introduced a factor characteristic model to control for factors that might simultaneously affect the health of all individuals, irrespective of their age. Findings on the period controls for economic shifts and medical progress showed that across our observation window (1992 until 2013), period effects on health were relatively weak. Moreover, these effects did not differ across educational groups, and inclusion of the period controls did not alter the estimates for age, cohort, and their interactions with education. These findings increase confidence that period effects, even if uncontrolled, are unlikely to bias estimates for cumulative advantage and rising importance.

Looking at the overall picture of current life course research on health inequality, this study's theoretical perspective and empirical results suggest that cumulative advantage of education for health is a context-specific phenomenon rather than a universal principle. As other comparative evidence remains scarce (Chen et al. 2010; van Kippersluis et al. 2010), future research along these lines holds great potential to advance our understanding of health inequality across lives and cohorts. Considering the vast cross-national differences in social stratification and welfare state intervention, inclusion of other country contexts can provide new answers to important questions: Under which conditions do social disparities in health 
accumulate faster or slower? What types of welfare state intervention may break the chains of accumulation?

It appears worthwhile to look at the egalitarian regimes of northern Europe in future tests of cumulative advantage and rising importance. Compared to Germany and the U.S., these countries offer more generous social policies and more equal chances in the educational and occupational systems, potentially offsetting any accumulation of health inequality over the life course (DiPrete 2002). In cross-sectional assessments, however, these countries have revealed sizable health gaps across various measures of socioeconomic position (Mackenbach 2012). These findings, currently discussed as the "Nordic paradox", might constitute a fruitful research problem to address on the basis of longitudinal data that will allow disentangling age and cohort effects. As these data are now available in many countries, studies along these lines will shed more light on processes of cumulative advantage and rising importance to help resolve the remaining puzzles of research on health inequality. 


\section{References}

Allmendinger, J. 1989. "Educational systems and labor market outcomes.” European Sociological Review. 5: 231-250.

Autor, D. H., L. F. Katz, \& A. B. Krueger. 1998. "Computing inequality: Have computers changed the labor market?” The Quarterly Journal of Economics. 113: 1169-1213.

Beckett, M. 2000. "Converging health inequalities in later life--an artifact of mortality selection?” Journal of Health \& Social Behavior. 41: 106-119.

Bell, A., \& K. Jones. 2014. “Another “futile quest?” A simulation study of Yang and Land 's Hierarchical Age-Period-Cohort model.” Demographic Research. 30: 333-360.

Blossfeld, H.-P. \& U. Jaenichen. 1992. "Educational Expansion and Changes in Women's Entry into Marriage and Motherhood in the Federal Republic of Germany.” Journal of Marriage and Family. 54: 302-315.

Blossfeld, H.-P. 2009. "Educational Assortative Marriage in Comparative Perspective” Annual Review of Sociology. 35: 513-530.

Blumenthal, D., E. Malphrus, \& Michael McGinnis (Eds.). 2015. Vital Signs: Core Metrics for Health and Health Care Progress. Institute of Medicine of the National Academies.

Chen, F., Y. Yang, \& G. Liu. 2010. "Social Change and Socioeconomic Disparities in Health over the Life Course in China: A Cohort Analysis.” American Sociological Review. 75: 126-150.

Clark, D. O. \& G. L. Maddox. 1992. "Racial and Social Correlates of Age-Related Changes in Functioning.” The Journals of Gerontology: Social Sciences. 47: S222-S232.

Cockerham, W. C., G. Kunz, G. Leuschen \& J. L Spaeth. 1986. Symptoms, social stratification and self-responsibility for health in the United States and West Germany.” Social Science \& Medicine. 22: 1263-1271.

Daly, M. C., F. Bu, \& G. J. Duncan. 2000. "Premiums and penalties for surplus and deficit education Evidence from the United States and Germany” Economics of Education Review. 19: 169-178.

Dannefer, D. 2003. “Cumulative Advantage/Disadvantage and the Life Course: Cross Fertilising Age and Social Science Theory.” The Journals of Gerontology: Social Sciences. 58: 327-337.

DiPrete, T. A. 2002. "Life Course Risks, Mobility Regimes, and Mobility Consequences: A Comparison of Sweden, Germany, and the United States.” American Journal of Sociology. 108: 267-309. 
DiPrete, T. A., G. M. Eirich, K. S. Cook, \& D. S. Massey. 2006. "Cumulative advantage as a mechanism for inequality: A Review of Theoretical and Empirical Developments.” Annual Review of Sociology. 32: 271-297.

Dustmann, C., J. Ludsteck, \& U. Schönberg. 2009. "Revisiting the German Wage Structure.” The Quarterly Journal of Economics. 124: 843-881.

Ehlert, M. 2012. "Buffering Income Loss Due to Unemployment. Family and Welfare State Influences on Income after Job Loss in the United States and western Germany.” Social Science Research. 41: 843-860.

Elo, I. T. \& S. H. Preston. 1996. “Educational differentials in mortality: United States, 19791985.” Social Science \& Medicine. 42: 47-57.

Esping-Andersen, G. 1994. "Welfare States and the Economy.” Pp. 711-732 in Handbook of Economic Sociology, edited by N. J. Smelser and R. Swedberg: Princeton University Press.

Fitzenberger, B. \& G. Wunderlich. 2003. “Gender Wage Differences in West Germany: A Cohort Analysis.” German Economic Review. 3: 379-414.

Freeman, R. B. 1994. “Working Under Different Rules.” New York: Russell Sage Foundation.

Gangl, M. 2004. "Welfare States and the Scar Effects of Unemployment: A Comparative Analysis of the United States and West Germany.” American Journal of Sociology. 109: 1319-1364.

Goldin, C. D. \& L. F. Katz. 2009. “The Race between Education and Technology.” Cambridge: Harvard University Press.

Goesling, B. 2007. “The Rising Significance of Education for Health?” Social Forces. 85: 1621-1644.

Haas, S. A. 2006. "Health Selection and the Process of Social Stratification: The Effect of Childhood Health on Socioeconomic Attainment.” Journal of Health and Social Behavior. 47: 339-354.

Harper, S. \& J. Lynch. 2007. "Trends in Socioeconomic Inequalities in Adult Health Behaviors Among U.S. States, 1990-2004.” Public Health Reports. 122: 177-189.

Hayward, M. D. \& B. K. Gorman. 2004. "The Long Arm of Childhood: The Influence of Early-Life Social Conditions on Men's Mortality.” Demography. 41: 87-107.

Herd, P. 2006. “Do Functional Health Inequalities Decrease in Old Age? Educational Status and Functional Decline Among the 1931-1941 Birth Cohort.” Research on Aging. 28: 375-392. 
Hoffmann, R. 2011. "Illness, Not Age, Is the Leveler of Social Mortality Differences in Old Age.” The Journals of Gerontology: Social Sciences: 66B: 374-379.

House, J. S., J. M. Lepkowski, A. M. Kinney, R. P. Mero, R. C. Kessler, \& R. A. Herzog. 1994. “The Social Stratification of Aging and Health.” Journal of Health \& Social Behavior. 35: 213-234.

Hout, M. 2012. "Social and Economic Returns to College Education in the United States." Annual Review of Sociology. 38: 379-400.

Idler, E. L. \& Y. Benyamini. 1997. "Self-Rated Health and Mortality: A Review of TwentySeven Community Studies.” Journal of Health and Social Behavior. 38: 21-37.

Jürges, H., S. Reinhold, \& M. Salm. 2011. “Does schooling affect health behavior? Evidence from the educational expansion in Western Germany.” Economics of Education Review: Special Issue on Education and Health. 30: 862-872.

Kerckhoff, A. C. 1995. "Institutional Arrangements and Stratification Processes in Industrial Societies.” Annual Review of Sociology. 21: 323-347

Kitagawa, E. M. \& P. M. Hauser. 1973. “Differential Mortality in the United States: A Study in Socioeconomic Epidemiology.” Cambridge: Harvard University Press.

Klein, M. 2011. "Trends in the association between educational attainment and class destinations in West Germany: Looking inside the service class.” Research in Social Stratification and Mobility. 29: 427-444.

Klein, T. \& R. Unger. 2001. "Einkommen, Gesundheit und Mortalität in Deutschland, Grossbritannien und den USA. ” Kölner Zeitschrift für Soziologie und Sozialpsychologie. 53: 96-110.

Knesebeck, O. v. d. 2005. "Soziale Einflüsse auf die Gesundheit alter Menschen. Eine deutsch-amerikanische Vergleichsstudie.” Bern: Verlag Hans Huber.

Kreyenfeld. M. 2010. “Uncertainties in Female Employment Careers and the Postponement of Parenthood in Germany.” European Sociological Review. 26: 351-366.

Kroll, L. E. 2010. "Sozialer Wandel, soziale Ungleichheit und Gesundheit. Die Entwicklung sozialer und gesundheitlicher Ungleichheiten in Deutschland zwischen 1984 und 2006.” Wiesbaden: VS Verlag.

Lauderdale, D. S. 2001. "Education and Survival: Birth Cohort, Period, and Age Effects." Demography. 38: 551-561.

Liu, H., \& R. A. Hummer. 2008. “Are Educational Differences in U.S. Self-Rated Health Increasing? An Examination by Gender and Race.” Social Science \& Medicine. 67: 1898-1906. 
Lleras-Muney, A., \& F. R, Lichtenberg. 2002. "The Effect of Education on Medical Technology Adoption: Are the More Educated More Likely to Use New Drugs?” NBER Working Paper No. 9185.

Lynch, S. M. 2003. “Cohort and Life-Course Patterns in the Relationship Between Education and Health: A Hierarchical Approach.” Demography. 40: 309-331.

Lynch, S. M. 2006. "Explaining Life Course and Cohort Variation in the Relationship between Education and Health: The Role of Income.” Journal of Health \& Social Behavior. 47: 324-338.

Mackenbach, J. P. 2012. "The persistence of health inequalities in modern welfare states: The explanation of a paradox.” Social Science \& Medicine. 75: 761-769.

Mayer, K. U. 2009. "Whose Lives? How History, Societies, and Institutions Define and Shape Life Courses.” Research in Human Development. 1: 161-187.

McEwen, B. S. 1998. "Stress, Adaptation, and Disease: Allostasis and Allostatic Load." Annals of the New York Academy of Sciences. 840: 33-44.

Matthews, S., O. Manor, \& C. Power. 1999. "Social inequalities in health: Are there gender differences?” Social Science \& Medicine. 48: 49-60.

Mirowsky, J., \& C. E. Ross (eds.). 2003. Education, Social Status and Health. New Brunswick, NJ: Aldine.

Mirowsky, J. \& C. E. Ross. 2008. "Education and Self-Rated Health: Cumulative Advantage and Its Rising Importance.” Research on Aging. 30: 93-122.

Mirowsky, J. \& C. E. Ross. 2007. "Life Course Trajectories of Perceived Control and Their Relationship to Education.” American Journal of Sociology. 112: 1339-1382.

Noymer, A. 2001. "Mortality Selection and Sample Selection: A Comment on Beckett.” Journal of Health and Social Behavior. 42: 326-327.

O’Brien, R.M. 2015. Age-Period-Cohort Models: Approaches and Analyses with Aggregate Data. Boca Raton: Taylor \& Francis Group, LLC.

O’Rand, A. M. 1996. “The Precious and Presocious: Understanding Cumulative Disadvantage and Cumulative Advantage over the Life Course.” The Gerontologist. 36: 230-238.

Pampel F. 2010. “Divergent Patterns of Smoking Across High-Income Nations.” Pp. 132163, in International Differences in Mortality at Older Ages: Dimensions and Sources, edited by E.M. Crimmins, S.H. Preston and B. Cohen. Washington (DC): National Academies Press. 
Pampel, F., Legleye, S., Goffette, C., Piontek, D., Kraus, L., \& Khlat, M. 2015. “Cohort Changes in Educational Disparities in Smoking: France, Germany and the United States.” Social Science and Medicine, 127, 41-50.

Pudrovska, T. 2014. "Early-Life Socioeconomic Status and Mortality at Three Life Course Stages: An Increasing Within-Cohort Inequality.” Journal of Health and Social Behavior. 55: 181-195.

Reczek, C. \& D. Umberson. 2012. “Gender, Health Behavior, and Intimate Relationships: Lesbian, Gay, and Straight Contexts.” Social Sciences \& Medicine. 74:1783-90.

Ross, C. E. \& C.-L. Wu. 1996. “Education, Age, and the Cumulative Advantage in Health.” Journal of Health \& Social Behavior. 37: 104-120.

Ross, C. E., \& J. Mirowsky. 2010. "Gender and the Heath Benefits of Education.” The Sociological Quarterly. 51: 1-19.

Ryder, N. B. 1965. “The cohort as a concept in the study of social change.” American Sociological Review. 30: 843-861.

Schöllgen, I., O. Huxhold, \& C. Tesch-Römer. 2010. "Socioeconomic status and health in the second half of life: findings from the German Ageing Survey.” European Journal of Ageing. 7: 17-28.

Shavit, Y., \& W. Müller. 1998. "From school to work: a comparative study of educational qualifications and occupational destinations.” New York: Clarendon Press.

Schulze, A., \& U. Mons. 2006. "The evolution of educational inequalities in smoking: a changing relationship and a cross-over effect among German birth cohorts of 1921-70.” Addiction. 7: 1051-1056.

Sørensen, A, \& H. Trappe. 1995. “The Persistence of Gender Inequality in Earnings in the German Democratic Republic.” American Sociological Review. 60: 398-406.

Solga H. 2002. “'Stigmatization by Negative Selection’: Explaining Less-Educated People’s Decreasing Employment Opportunities.” European Sociological Review. 18: 159-178.

Specht, J., B. Egloff, \& S. C. Schmukle. 2013. "Everything under control? The effects of age, gender, and education on trajectories of perceived control in a nationally representative German sample.” Developmental Psychology. 49: 353-364.

Tapia-Granados, J. 2005. “Increasing mortality during the expansions of the US economy, 1900-1996.” International Journal of Epidemiology. 34: 1194-202.

van Kippersluis, H., O.O. Donnell, E. van Doorslaer, \& T. van Ourti. 2010. "Socioeconomic differences in health over the life cycle in an Egalitarian country.” Social Science \& Medicine. 70: 428-438. 
Wagner, G. G., J. R. Frick, \& J. Schupp. 2007. “The German Socio-Economic Panel Study (SOEP) - Scope, Evolution and Enhancements.” Schmollers Jahrbuch. 127: 139-169.

Willson, A. E., K. M. Shuey, \& G. H. Elder Jr. 2007. “Cumulative Advantage Processes as Mechanisms of Inequality in Life Course Health.” American Journal of Sociology. 112: 1886-1924.

Wysong, J. A., \& T. Abel. 1990. "Universal health insurance and high-risk groups in West Germany: implications for U.S. health policy.” The Milbank Quarterly. 68: 527-560.

Zajacova, A., R. G. Rogers, \& V. Johnson-Lawrence. 2012. "Glitch in the gradient: Additional education does not uniformly equal better health.” Social Science \& Medicine. 75: 2007-2012. 
TABle 1. Cumulative AdVANTAGE AND Rising IMPORTANCE IN GERMANY AND the U.S.

\begin{tabular}{|c|c|c|c|c|}
\hline Hypothesis & Argument & $\mathrm{DE}$ & US & Empirical evidence \\
\hline \multicolumn{5}{|l|}{ Cumulative advantage } \\
\hline \multirow[t]{2}{*}{ Education } & School as a sorting machine & & $>$ & Allmendinger 1989 \\
\hline & $\begin{array}{l}\text { Education as a predictor } \\
\text { of SES across the life-course }\end{array}$ & & $>$ & Shavit and Müller 1998 \\
\hline \multirow{3}{*}{$\begin{array}{l}\text { Labor market } \\
\text { factors }\end{array}$} & Inequality in income & & $<$ & Freeman 1994 \\
\hline & $\begin{array}{l}\text { Inequality in } \\
\text { unemployment risks }\end{array}$ & & $<$ & Gangl 2004 \\
\hline & $\begin{array}{l}\text { Lack of social protection } \\
\text { against risks }\end{array}$ & & $<$ & $\begin{array}{l}\text { Ehlert } 2012 \\
\text { Esping-Andersen } 1994\end{array}$ \\
\hline Health care & Inequality in access & & $<$ & $\begin{array}{l}\text { Wysong and Abel } 1990 \\
\text { Knesebeck et al. } 2003\end{array}$ \\
\hline $\begin{array}{l}\text { Psychosocial } \\
\text { factors }\end{array}$ & $\begin{array}{l}\text { Inequality in stress from } \\
\text { life events }\end{array}$ & & $<$ & $\begin{array}{l}\text { DiPrete } 2002 \\
\text { Mayer } 2009\end{array}$ \\
\hline Health behaviors & $\begin{array}{l}\text { Inequality in smoking } \\
\text { and physical activity }\end{array}$ & & $<$ & $\begin{array}{l}\text { Cockerham et al. } 1986 \\
\text { Cockerham et al. } 1988 \\
\text { Pampel } 2010\end{array}$ \\
\hline $\begin{array}{l}\text { Health-relevant } \\
\text { competencies }\end{array}$ & $\begin{array}{l}\text { Inequality in sense of } \\
\text { personal control }\end{array}$ & & $<$ & $\begin{array}{l}\text { Mirowky and Ross } 2007 \\
\text { Specht et al. } 2013\end{array}$ \\
\hline \multicolumn{5}{|l|}{ Rising Importance } \\
\hline \multirow[t]{2}{*}{$\begin{array}{l}\text { Distribution and } \\
\text { use of health- } \\
\text { related resources }\end{array}$} & $\begin{array}{l}\text { Rising inequality in } \\
\text { economic returns to education }\end{array}$ & & $<$ & $\begin{array}{l}\text { Dustmann et al. } 2009 \\
\text { Freeman } 1994 \\
\text { Solga } 2002\end{array}$ \\
\hline & $\begin{array}{l}\text { Rising inequality in the ability } \\
\text { to benefit from health } \\
\text { knowledge }\end{array}$ & & $<$ & $\begin{array}{l}\text { Harper and Lynch } 2007 \\
\text { Schulze and Mons } 2006\end{array}$ \\
\hline $\begin{array}{l}\text { Compositional } \\
\text { change }\end{array}$ & $\begin{array}{l}\text { Increasing selectivity of } \\
\text { educational groups }\end{array}$ & & $>$ & $\begin{array}{l}\text { Goldin and Katz } 2009 \\
\text { Solga } 2002\end{array}$ \\
\hline
\end{tabular}


TABLE 2. DesCriptive STATISTICS: TOTAL SAMPLE AND SEPARATELY By COHORTS

\begin{tabular}{|c|c|c|c|c|c|c|c|c|c|c|c|c|c|c|c|c|}
\hline & \multirow{2}{*}{\multicolumn{4}{|c|}{ Total }} & \multirow{2}{*}{\multicolumn{4}{|c|}{$\begin{array}{l}\text { Pre-war and war cohorts } \\
\text { 1930-45 }\end{array}$}} & \multirow{2}{*}{\multicolumn{4}{|c|}{$\begin{array}{c}\text { Post war cohorts } \\
\text { 1946-56 }\end{array}$}} & \multirow{2}{*}{\multicolumn{4}{|c|}{$\begin{array}{c}\text { Baby boom cohorts } \\
1957-68\end{array}$}} \\
\hline & & & & & & & & & & & & & & & & \\
\hline & Mean & SD & Min & Max & Mean & SD & Min & Max & Mean & SD & Min & Max & Mean & SD & Min & Max \\
\hline Self-rated health ${ }^{\mathrm{a}}$ & 3.28 & 0.92 & 1 & 5 & 2.98 & 0.91 & 1 & 5 & 3.24 & 0.90 & 1 & 5 & 3.56 & 0.85 & 1 & 5 \\
\hline Age & 49.5 & 12.7 & 24 & 83 & 62.8 & 7.34 & 47 & 83 & 49.6 & 6.96 & 36 & 67 & 38.0 & 7.05 & 24 & 56 \\
\hline Median-centered & 0.46 & 12.7 & -25 & 34 & & & & & & & & & & & & \\
\hline \multicolumn{17}{|l|}{ Cohort } \\
\hline Year of birth & 1951 & 11.2 & 1930 & 1968 & 1938 & 4.3 & 1930 & 1945 & 1951 & 3.2 & 1946 & 1956 & 1963 & 3.4 & 1957 & 1968 \\
\hline Age in 1992 & 41 & 11.2 & 24 & 62 & & & & & & & & & & & & \\
\hline Mean-centered & 0 & 11.2 & -17 & 21 & & & & & & & & & & & & \\
\hline \multicolumn{17}{|l|}{ Education $^{\mathrm{b}}$} \\
\hline Intermediate & 0.33 & & 0 & 1 & 0.22 & & 0 & 1 & 0.30 & & 0 & 1 & 0.43 & & 0 & 1 \\
\hline Higher & 0.16 & & 0 & 1 & 0.11 & & 0 & 1 & 0.17 & & 0 & 1 & 0.19 & & 0 & 1 \\
\hline Male & 0.49 & & 0 & 1 & 0.49 & & 0 & 1 & 0.49 & & 0 & 1 & 0.50 & & 0 & 1 \\
\hline \multicolumn{17}{|l|}{ Dropout } \\
\hline Died & 0.09 & & 0 & 1 & 0.21 & & 0 & 1 & 0.06 & & 0 & 1 & 0.02 & & 0 & 1 \\
\hline Left panel & 0.59 & & 0 & 1 & 0.55 & & 0 & 1 & 0.59 & & 0 & 1 & 0.62 & & 0 & 1 \\
\hline Obs. per individual & 14.8 & 7.26 & 1 & 22 & 14.7 & 7.35 & 1 & 22 & 14.9 & 7.23 & 1 & 22 & 148 & 7.20 & 1 & 22 \\
\hline$N$ (observations) & 68,402 & & & & 22,715 & & & & 18,897 & & & & 26,790 & & & \\
\hline$N$ (individuals) & 4,629 & & & & 1,550 & & & & 1,266 & & & & 1,813 & & & \\
\hline
\end{tabular}

SOEP, release 2014. ${ }^{\text {a }}$-point scale, reverse coded $\left(1=\right.$ bad, 5 = very good). ${ }^{b}$ Lower $=$ CASMIN $1 \mathrm{a}-\mathrm{c}$ (up to lower secondary vocational degree); intermediate $=$ CASMIN 2a-c (up to higher secondary plus vocational training); higher = CASMIN 3a-b (lower and higher tertiary). 


\begin{tabular}{|c|c|c|c|c|c|c|}
\hline \multirow[b]{2}{*}{ Intercept } & \multicolumn{2}{|c|}{ Model 1: Total } & \multicolumn{2}{|c|}{ Model 2: Men } & \multicolumn{2}{|c|}{ Model 3: Women } \\
\hline & $3.190 * *$ & $(0.022)$ & $3.231^{* *}$ & $(0.029)$ & $3.224 * *$ & $(0.028)$ \\
\hline Age (median-centered) & $-0.026 * *$ & $(0.001)$ & $-0.029 * *$ & $(0.002)$ & $-0.024 * *$ & $(0.002)$ \\
\hline Cohort (mean-centered) ${ }^{\mathrm{a}}$ & $0.005^{*}$ & $(0.002)$ & $0.006^{*}$ & $(0.003)$ & 0.003 & $(0.003)$ \\
\hline \multicolumn{7}{|l|}{ Education (ref.: Lower) ${ }^{\mathrm{b}}$} \\
\hline Intermediate & $0.182 * *$ & $(0.025)$ & $0.185^{* *}$ & $(0.037)$ & $0.171^{* *}$ & $(0.034)$ \\
\hline Higher & $0.302 * *$ & $(0.032)$ & $0.327 * *$ & $(0.040)$ & $0.279 * *$ & $(0.052)$ \\
\hline Age x Cohort (/100) & 0.006 & $(0.008)$ & 0.017 & $(0.012)$ & -0.008 & $(0.011)$ \\
\hline \multicolumn{7}{|l|}{ Age $\mathrm{x}$ Education } \\
\hline Age x Intermediate & 0.000 & $(0.002)$ & 0.002 & $(0.002)$ & -0.001 & $(0.002)$ \\
\hline Age x Higher & $0.005^{* *}$ & $(0.002)$ & $0.012 * *$ & $(0.003)$ & -0.003 & $(0.003)$ \\
\hline \multicolumn{7}{|l|}{ Cohort x Education } \\
\hline Cohort x Intermediate & 0.003 & $(0.002)$ & 0.006 & $(0.004)$ & 0.003 & $(0.003)$ \\
\hline Cohort x Higher & -0.006 & $(0.003)$ & $-0.012^{* *}$ & $(0.004)$ & 0.003 & $(0.005)$ \\
\hline \multicolumn{7}{|l|}{ Age $x$ Cohort $x$ Education } \\
\hline Age x Cohort x Intermediate (/100) & -0.016 & $(0.013)$ & -0.004 & $(0.020)$ & -0.016 & $(0.017)$ \\
\hline Age x Cohort x Higher (/100) & -0.052 & $(0.017)$ & -0.020 & $(0.022)$ & 0.022 & $(0.029)$ \\
\hline Male & $0.071^{* *}$ & $(0.020)$ & & & & \\
\hline \multicolumn{7}{|l|}{ Period controls (all mean-centered) } \\
\hline Unemployment rate & $-0.130 * *$ & $(0.026)$ & $-0.160 * *$ & $(0.037)$ & $-0.102^{* *}$ & $(0.037)$ \\
\hline Unemployment rate squared & $0.006 * *$ & $(0.001)$ & $0.008^{* *}$ & $(0.002)$ & $0.005^{*}$ & $(0.002)$ \\
\hline GDP & -0.003 & $(0.002)$ & -0.002 & $(0.002)$ & -0.004 & $(0.002)$ \\
\hline Population wellbeing & $0.100 * *$ & $(0.029)$ & 0.077 & $(0.041)$ & $0.121^{* *}$ & $(0.041)$ \\
\hline Health expenditures & $-0.027^{*}$ & $(0.014)$ & $-0.042 *$ & $(0.020)$ & -0.014 & $(0.020)$ \\
\hline \multicolumn{7}{|l|}{ Variance components } \\
\hline Residual (Level 1) & $0.353 * *$ & & $0.334 * *$ & & $0.370 * *$ & \\
\hline Intercept & $0.361 * *$ & & $0.367 * *$ & & $0.355^{* *}$ & \\
\hline Age & $0.001 * *$ & & $0.001^{* *}$ & & $0.001 * *$ & \\
\hline Covariance of intercept and age & $0.003^{*}$ & & $0.003^{*}$ & & $0.002 *$ & \\
\hline$N$ (observations) & \multicolumn{2}{|c|}{63,889} & \multicolumn{2}{|c|}{30,858} & \multicolumn{2}{|c|}{33,031} \\
\hline
\end{tabular}

SOEP, release 2014. Standard errors in parentheses. All models control for panel attrition due to nonresponse and death. ${ }^{a}$ Centered on the mean age of sample entry, age 41 (i.e., birth cohort of 1951). ${ }^{b}$ Lower = CASMIN 1a-c (up to lower secondary vocational degree); intermediate = CASMIN 2a-c (up to higher secondary plus vocational training); higher = CASMIN 3a-b (lower and higher tertiary). $\mathrm{p}<0.01,{ }^{*} \mathrm{p}<0.05$. 
Model 4

Intercept

Age $^{a}$

$-0.022 * *$

Cohort (ref.: Pre-War \& War)

Post-War

Baby Boom

Education (ref.: Lower) ${ }^{\mathrm{b}}$

Intermediate

Higher

Age $x$ Cohort

$$
\begin{aligned}
& \text { Age x Post-War } \\
& \text { Age x Baby Boom }
\end{aligned}
$$

Age $x$ Education

Age x Intermediate

Age $x$ Higher

Cohort x Education

$$
\text { Post-War x Intermediate }
$$

Baby Boom x Intermediate

Post-War x Higher

Baby Boom x Higher

Age x Cohort x Education

Age x Post-War x Intermediate

Age x Baby Boom x Intermediate

Age $\mathrm{x}$ Post-War $\mathrm{x}$ Higher

Age x Baby Boom x Higher

Period controls (all mean-centered)

Unemployment rate
Unemployment rate squared

GDP

Wellbeing

Health expenditures

Variance components

$$
\begin{aligned}
& \text { Residual (Level 1) } \\
& \text { Intercept }
\end{aligned}
$$

$0.229 * *$

$0.562 * *$

$0.261 * *$

0.136

$-0.010 * *$

$-0.007^{* *}$

$-0.002$

$0.009 * *$

$-0.123$

$-0.214^{*}$

0.041

$-0.031$

0.008*

0.004

0.004

0.004

$-0.173^{* *}$

$0.009 * *$

$-0.003$

0.087*

$-0.051 * *$

$N$ (observations)

$0.356^{* *}$

$0.368 * *$ 30,858

SOEP, release 2014. Standard errors in parentheses. All models control for panel attrition due to nonresponse and death. ${ }^{a}$ Centered on the cohort-specific minimum ages (47 in the Pre-War \& War cohort, 36 in the Post-War cohort, 24 in the Baby Boom cohort). ${ }^{\mathrm{b}}$ Lower = CASMIN 1a-c (up to lower secondary vocational degree); intermediate = CASMIN 2a-c (up to higher secondary plus vocational training); higher = CASMIN 3a-b (lower and higher tertiary). ${ }^{* *} \mathrm{p}$ $<0.01, * \mathrm{p}<0.05$. 
Table 5: Health Gaps Between Higher and Lower Educated Men at Overlapping Ages

\begin{tabular}{lcccc}
\hline \multirow{2}{*}{ Cohort } & \multicolumn{4}{c}{ Health Gaps Between Higher and Lower Educated Men at Age } \\
\cline { 2 - 5 } & 36 & 47 & 56 & 67 \\
\hline $\begin{array}{l}\text { Pre-war \& war } \\
1930-45\end{array}$ & & 0.14 & 0.21 & 0.31 \\
$\begin{array}{l}\text { Post-war } \\
\text { 1946-56 }\end{array}$ & 0.18 & 0.32 & 0.43 & 0.57 \\
$\begin{array}{l}\text { Baby boom } \\
1957-68\end{array}$ & 0.26 & 0.40 & 0.52 & \\
\hline
\end{tabular}

SOEP, release 2014. Predictions are based on Model 4, Table 4. Gaps are measured as absolute differences in scale points of self-rated health ( $S D$ of within-person change over time in self-rated health is 0.61 ). See Figure 4 for a graphical illustration of health gaps. 


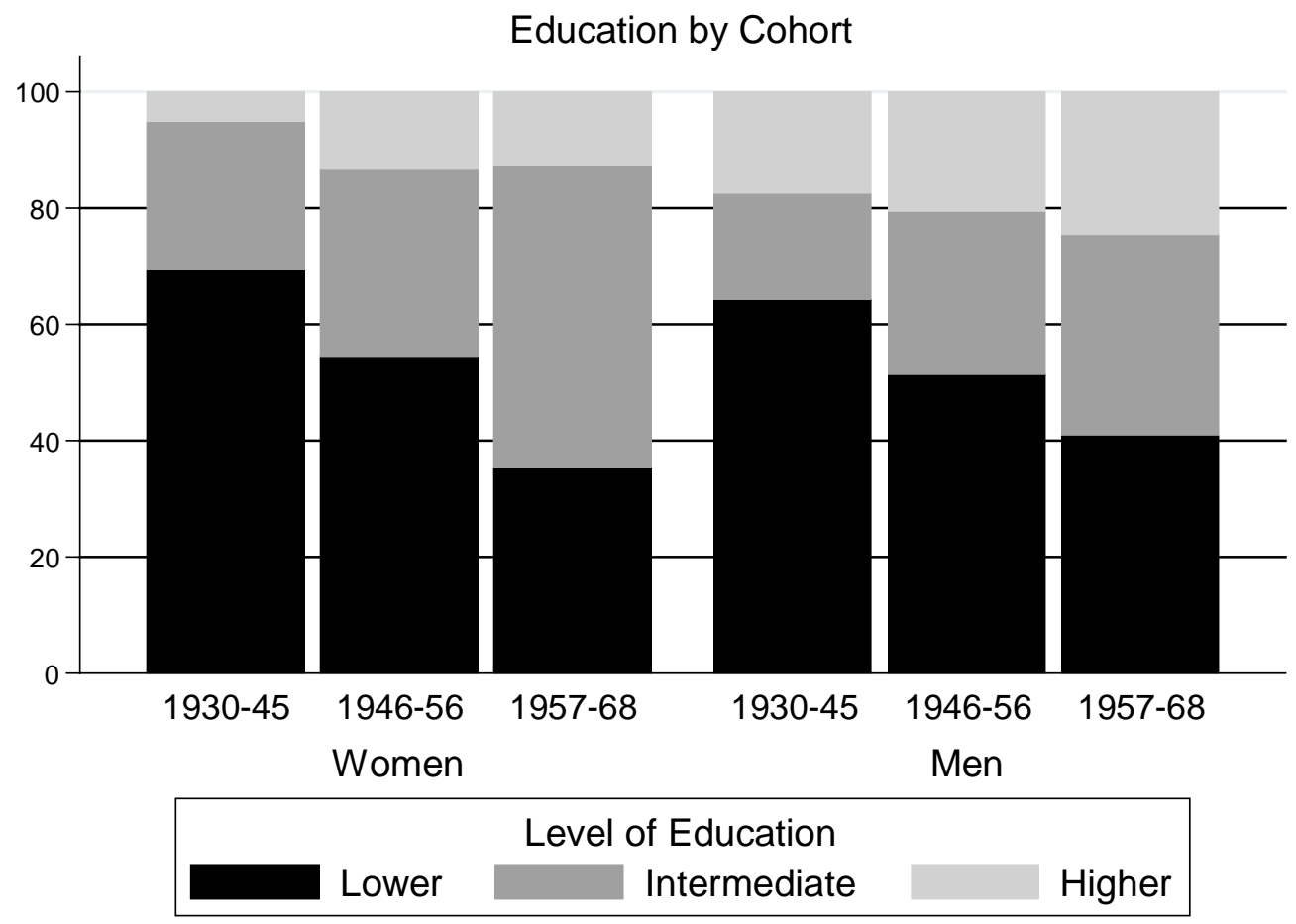

Figure 1: DistRIBUTION OF EDUCATIONAL LEVELS By COHORT

SOEP, release 2014. $N=4,629$. Lower education $=$ up to lower secondary vocational degree (CASMIN 1a-c). Intermediate education $=$ up to higher secondary degree plus vocational training (CASMIN 2a-c). Higher education = lower and higher tertiary degree (CASMIN 3a-b). 


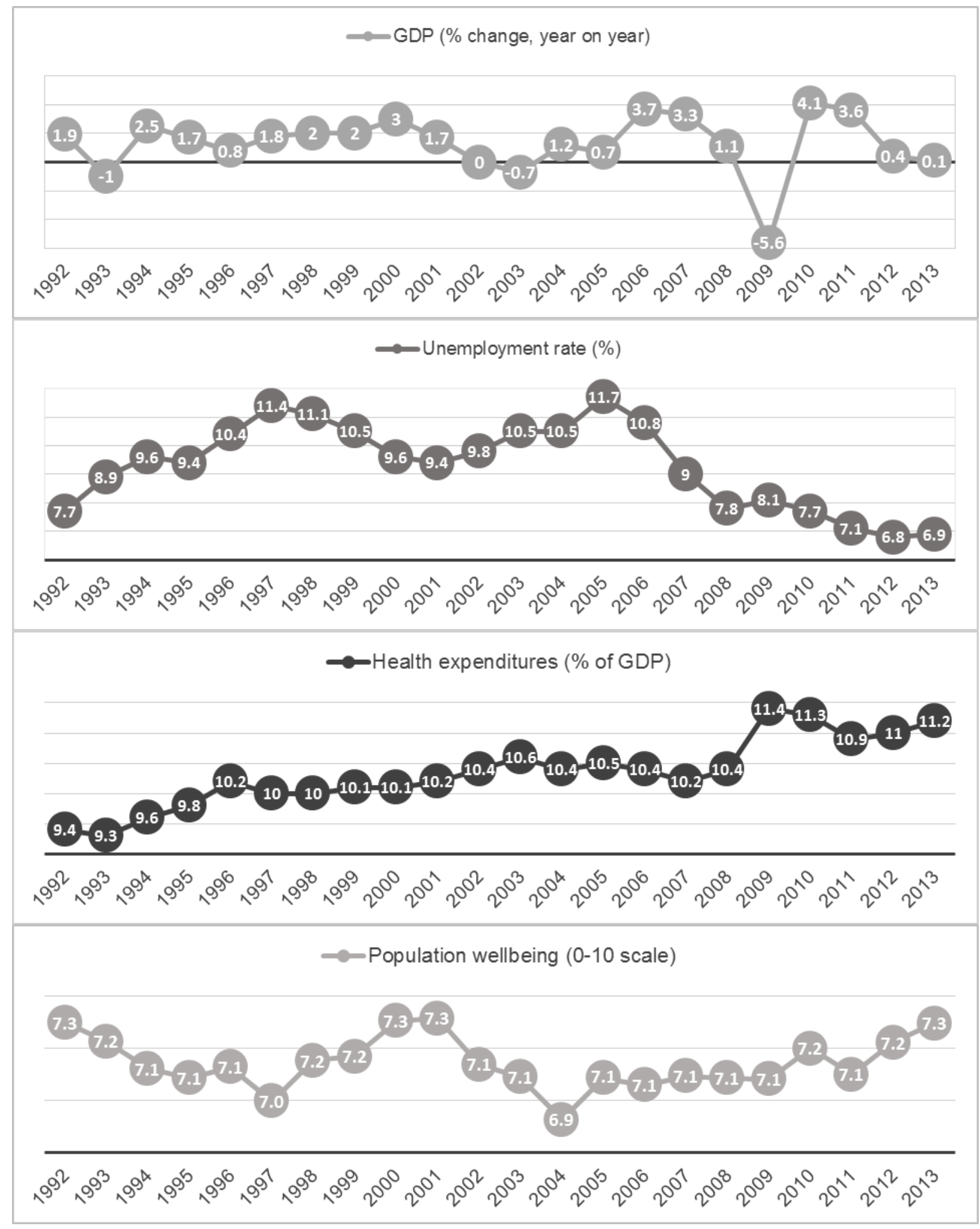

FigURE 2. CHANGES IN FACTOR CHARACTERISTIC VARIABLES ACROSS THE OBSERVATION PERIOD

Data on GDP, unemployment rates, and health expenditures are from the Federal Statistical Office. Data on population wellbeing are from the SOEP samples of West German natives $(N=215,081$ observations; authors' calculations). 

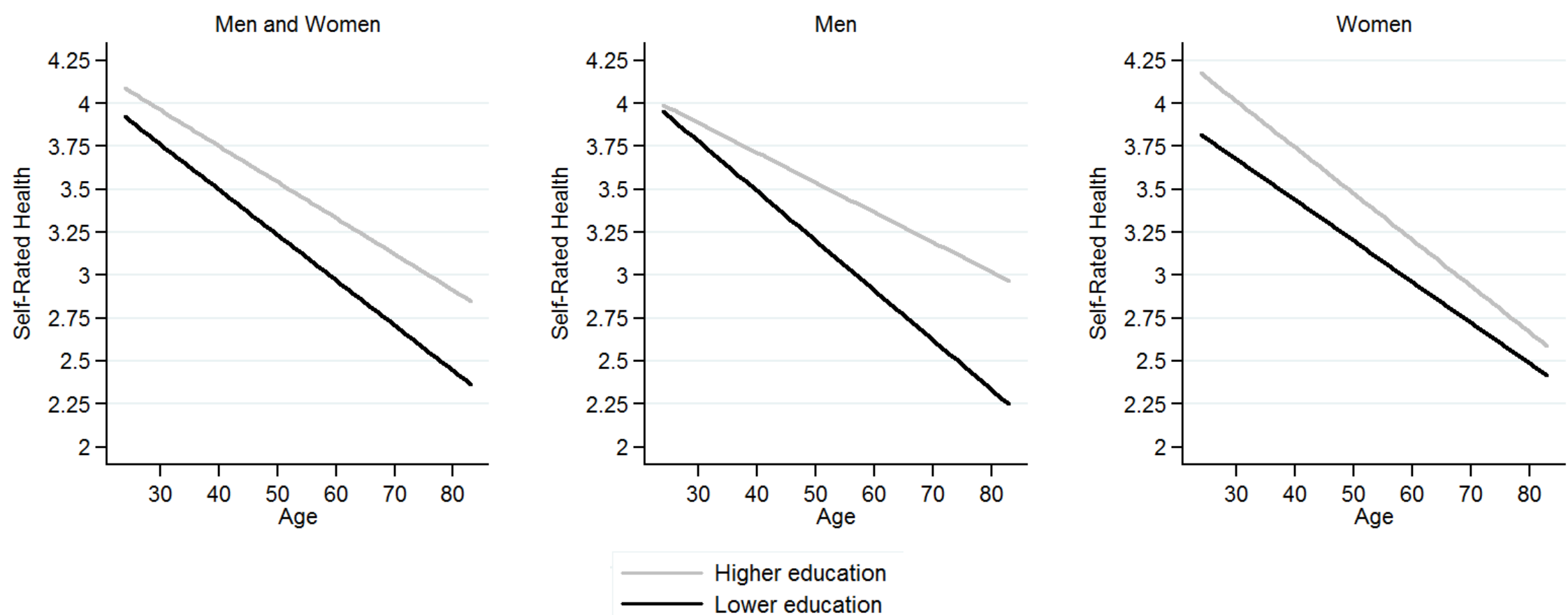

Figure 3: Predicted Trajectories of Self-Rated Health: Full Sample, Men, and Women

SOEP, release 2014. Predictions based on Model 1(full sample) Model 2 (male subsample) and Model 3 (female subsample). See Table 3 for details on the estimation. Cohort centered at 1951, remaining covariates fixed at their means. Lower education $=$ up to lower secondary vocational degrees $($ CASMIN 1a-c). Higher education = lower and higher tertiary degrees (CASMIN 3a-b). 


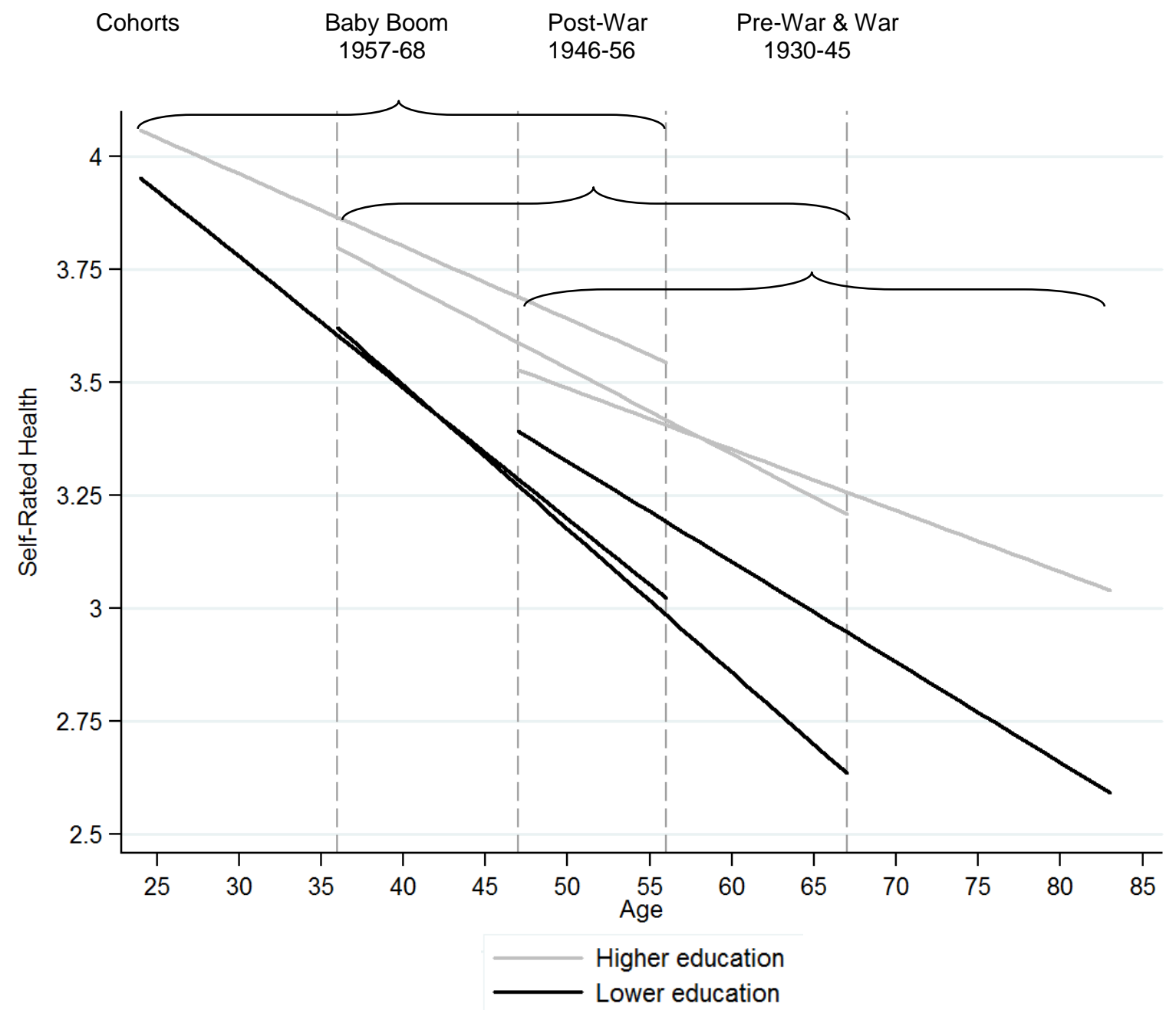

Figure 4: Predicted Trajectories of Self-Rated Health in Three Cohorts of Men

SOEP, release 2014. Predictions based on Model 4, Table 4. Age centered at cohort-specific minimum values (47 in the Pre-War \& War cohort, 36 in the Post-War cohort, 24 in the Baby Boom cohort), other covariates fixed at their means. Vertical dashed lines indicate lower and upper boundaries of age overlaps between cohorts (see Table 5). Lower education = up to lower secondary vocational degrees (CASMIN 1a-c). Higher education = lower and higher tertiary degrees (CASMIN 3a-b). 